\title{
IMPLEMENTASI INOVASI PADA MODEL-MODEL PENDIDIKAN ANAK USIA DINI DI TAMAN PENGASUHAN ANAK (TPA) SERAMA KEMENTERIAN KESEHATAN RI
}

\author{
ABDUL AZIZ \\ Pusat Analisis Determinan Kesehatan, Kementerian Kesehatan RI ${ }^{1}$ \\ Program Vokasi, Universitas Indonesia ${ }^{2}$ \\ E-mail: aziz_fatma9@yahoo.com
}

\begin{abstract}
The purpose of this paper is to describe the implementation of early childhood education model and its innovation in Daycare SERAMA Ministry of Health RI. This research applied descriptive qualitative design. The subject of this research was 10 students and their teacher. From this research, it showed that model full day program is in accordance with daycare SERAMA of the Ministry of Health and implementation of BCCT learning process can take place optimally The Expectation is that it can be used as a reference in making daycare in government institutions in providing the right and best education according to their interests, talents and abilities. Thus, the more variety and innovation of early childhood education will be able to support the development of children optimally, so it is creating a more moral and qualified Indonesian children.
\end{abstract}

Keywords: innovation, early childhood education model, and daycare

\begin{abstract}
Abstrak: Tujuan dari penulisan ini adalah untuk mendapatkan gambaran implementasi model pendidikan anak usia dini beserta inovasinya di TPA SERAMA Kementerian Kesehatan RI. Penelitian ini menggunakan desain deskriptif kualitatif. Subjek penelitian ini adalah 10 orang siswa dan dua guru mereka. Hasil penelitian menunjukkan bahwa model program fullday sangat sesuai dengan TPA SERAMA Kementerian Kesehatan RI dan pelaksanaan proses pembelajaran BCCT pun dapat berlangsung secara optimal Harapannya adalah agar dapat dijadikan sebagai rujukan dalam membuat TPA di institusi pemerintah dalam memberikan pendidikan yang tepat dan terbaik sesuai dengan minat, bakat, dan kemampuan masing-masing. Dengan demikian, semakin banyak ragam dan inovasi pendidikan anak usia dini akan mendukung perkembangan anak secara optimal, sehingga mampu mewujudkan anak Indonesia yang lebih bermoral dan berkualitas.
\end{abstract}

Kata Kunci: inovasi, model pendidikan anak usia dini, dan TPA

\section{PENDAHULUAN}

Masyarakat Indonesia telah mengakui pentingnya pendidikan bagi anak usia dini. Pemberian pendidikan pada anak usia dini merupakan langkah yang benar dan tepat. Rentang usia dini merupakan waktu yang tepat dalam mengembangkan potensi dan kecerdasan anak. Pada rentang usia dini, anak berada dalam proses 
pertumbuhan dan perkembangan yang unik (Eva, 2014).

Beberapa pakar pendidikan menyebutkan bahwa anak usia dini merupakan masa keemasan anak (the golden age). Pada kajian neurosains disebutkan bahwa, setiap anak yang baru dilahirkan perkembangan sel saraf pada otak mencapai $25 \%$, sampai usia 4 tahun mengalami perkembangan $50 \%$, dan sampai usia 8 tahun mencapai $80 \%$, selebihnya berkembang sampai usia 18 tahun (Mulyasa, 2012). Kajian neurosains tersebut memberikan gambaran bahwa perkembangan kecerdasan anak yang paling dominan terjadi pada usia $0-8$ tahun. Apabila anak diberikan stimulasi secara intensif dari lingkungannya, maka anak akan mampu menjalani tugas perkembangannya dengan baik (Laura, 2012). Oleh karena itu, pada masa ini harus dimanfaatkan dan dioptimalkan sebaik-baiknya dalam mengimplementasikan pendidikan anak usia dini.

Implementasi pendidikan anak usia dini di Indonesia mulai mendapat perhatian yang cukup serius oleh pemerintah. Pemerintah Indonesia 202 melakukan beberapa upaya dalam mengimplementasikan pendidikan anak usia dini di Indonesia dengan menerbitkan undang-undang dan peraturan menteri yang berhubungan dengan pendidikan anak usia dini. Pada Undang-Undang No. 20 tahun 2003 tentang Sistem Pendidikan Nasional disebutkan bahwa pendidikan anak usia dini adalah suatu upaya pembinaan yang ditujukan kepada anak sejak lahir sampai dengan usia enam tahun yang dilakukan melalui pemberian rangsangan pendidikan untuk membantu pertumbuhan dan perkembangan jasmani dan rohani agar anak memiliki kesiapan dalam memasuki pendidikan lebih lanjut. Adapun dalam lingkup internasional pendidikan anak usia dini sering disebut dengan istilah Early Childhood Education, yaitu suatu pendidikan yang diberikan pada awal masa anak (Mulyasa, 2012). Hal ini mengacu pada asosiasi pendidikan anak usia dini di Amerika Serikat yang biasa dikenal dengan sebutan The National Association of Education for Young Children (NAEYC). Kebanyakan pelaksanaan dan pengembangan pendidikan anak usia 
dini di sebagian besar dunia mengacu pada asosiasi ini (Slamet Suyanto, 2005).

Implementasi pendidikan anak usia dini di Indonesia bentuknya sudah sangat beragam, baik dalam lingkup pendidikan formal maupun nonformal. Sebagaimana disebutkan dalam Undang-undang No. 20 tahun 2003 bagian ketujuh Pasal 28 yang menyatakan bahwa bentuk pendidikan anak usia dini salah satunya dapat berupa Taman Penitipan Anak (TPA). Adapun menurut NAEYC, salah satu jenis layanan pendidikan anak usia dini adalah Taman Penitipan Anak (TPA) (Siti Aisyah dkk, 2015).

Pemerintah Indonesia juga memberikan kesempatan yang seluasluasnya kepada masyarakat untuk berpartisipasi dalam melaksanakan kegiatan-kegiatan pendidikan anak usia dini, baik formal, nonformal, maupun informal. Melalui upayaupaya yang telah ditempuh, pemerintah berharap pendidikan anak usia dini di Indonesia dapat berkembang dengan baik, sehingga tumbuh kembang anak dapat terlayani secara optimal. Namun melihat kondisi di lapangan dengan banyaknya
Pegawai Negeri Sipil (PNS) perempuan yang mencapai 49,31\% (BPS, 2017). Jumlah PNS perempuan menurun secara signifikan dari bulan Desember 2015 sampai Desember 2016 berkurang menjadi 2,15 juta yang $71,71 \%$ berada pada usia reproduksi (BPS, 2017). Hal ini mengakibatkan anak tidak memperoleh kebutuhan dasar, baik kebutuhan fisik, kasih sayang, dan pendidikan yang seharusnya menjadi tanggung jawab orang tua (terutama ibu) untuk proses tumbuh kembangnya tidak terpenuhi secara optimal.

Melihat permasalahan tersebut, dibutuhkan suatu wadah untuk perawatan serta pengembangan anak usia dini baik dari segi pengasuhan, gizi dan kesehatan yang dapat ditempuh melalui pendidikan non formal sebagai dasar awal pendidikan anak usia dini berupa Tempat Penitipan Anak (TPA). Dimana jumlah PNS perempuan di lingkungan Kementerian Kesehatan RI sebanyak 31.467 orang (61 \%) (Biro Kepegawaian Kementerian Kesehatan RI, 2017). Diharapkan dengan adanya TPA di lingkungan Kementerian Kesehatan RI, anak akan selalu 
mendapat kecukupan kebutuhan dasar dan terlindung dari bahaya yang mungkin terjadi (kecelakaan, penganiayaan, infeksi, kurang stimulasi, kurang gizi, dan lain sebagainya), sehingga anak akan mendapatkan perhatian dalam tumbuh kembang secara optimal sementara orang tua khususnya ibu dapat bekerja di luar rumah dengan tenang.

Berkaitan dengan implementasi pendidikan anak usia dini khususnya TPA di lingkungan Kementerian Kesehatan RI juga dapat dilihat melalui berbagai macam bentuk dan model maupun berbagai inovasi yang dikembangkan dalam pendidikan anak usia dini. Lantas seperti apa bentuk, model, dan inovasi pendidikan anak usia dini khususnya di TPA SERAMA Kementerian Kesehatan RI? dan bagaimana implementasinya?

\section{KAJIAN TEORITIK}

\section{Taman Pengasuhan Anak (TPA)}

TPA sebagai salah satu bentuk pendidikan anak usia dini yang membantu orangtua dalam pembentukan pribadi anak agar dapat mandiri. TPA lebih banyak dikelola oleh sebagian orang atau lembaga 204 pendidikan yang mampu tetapi belum didukung oleh guru yang profesional. TPA perlu disiapkan alat permainan yang banyak jenis ragamnya yang dapat mengembangkan berbagai aspek kepribadian. TPA diharapkan menjadi tempat yang ideal bagi anak supaya dapat membentuk pribadi anak (Soegeng, 2011).

Menurut Soegeng (2011), secara umum tujuan TPA adalah memberi peluang yang seluas-luasnya kepada anak untuk bermain; memberi kesempatan bagi anak mengembangkan potensinya; mengembangkan psikososial anak melalui pergaulan; melatih anak untuk bertanggung jawab, penanaman toleransi, etika, moral, agama, dan kerjasama; melatih keterampilan anak sehingga menjadi sehat; memberi suasana yang senang bagi anak; membantu orangtua dalam pendidikan dan pembentukan puteranya, dan melatih kecerdasan (intelektual, emosional, dan spiritual) anak melalui sarana dan alat permainan yang tersedia. TPA juga memilki keuntungan sebagai berikut seperti memenuhi persyaratan standar minimal, sehingga pelaksanaan 
kegiatan berjalan lancar; orangtua tidak selalu khawatir, karena ada pendidik yang bertanggung jawab; semua aspek kepribadiannya berkembang secara wajar; anak selalu senang karena banyak permainan; beban orangtua berkurang; jadwal kegiatan lebih fleksibel; pendidikan anak akan ditangani oleh orang yang profesional; mendapatkan kesempatan untuk bersosialisasi; memperoleh pengasuhan sesuai dengan lingkungan keluarga; dan risiko anak tertukar penyakit akan lebih kecil.

Menurut Depdiknas (Yuliani, 2009), TPA adalah wahana pendidikan dan pembinaan kesejahteraan anak yang berfungsi sebagai pengganti keluarga untuk jangka waktu tertentu selama orang tuanya berhalangan atau tidak memiliki waktu yang cukup dalam mengasuh anaknya karena bekerja atau sebab lain. Pendapat lain menyebutkan bahwa TPA adalah sarana pengasuhan dalam kelompok, biasanya dilaksanakan pada jam kerja dan merupakan upaya terorganisasi untuk mengasuh anak-anak di luar rumah mereka selama beberapa jam dalam satu hari bilamana asuhan orang tua kurang dapat dilaksanakan secara lengkap. Fungsi TPA menurut Direktorat PAUD (Sherly, 2013) sebagai wahana pendidikan dan pembinaan kesejahteraan anak yang berfungsi sebagai pengganti keluarga untuk jangka waktu tertentu. Selama orangtuanya berhalangan atau tidak memiliki waktu yang cukup dalam mengasuh anaknya karena bekerja atau sebab lain.

Bentuk TPA di Indonesia sangat beragam, karena harus menyesuaikan dengan lingkungan orangtuanya bekerja. Sekarang ini TPA telah dibuat dan didirikan dibeberapa area, seperti area perkantoran, pasar, perkebunan, dan rumah sakit. Hal ini dimaksudkan agar orangtua yang bekerja dapat langsung menitipkan anaknya di lingkungan di mana mereka bekerja. Tujuannya selain lebih aman, orangtua jauh lebih efektif dalam mengawasi dan mengantarkan buah hatinya.

\section{Model dan Inovasi Pendidikan Anak} Usia Dini

Model dan inovasi pendidikan anak usia dini di Indonesia sudah mulai menunjukkan suatu kemajuan. Model dan inovasi ini dimaksudkan untuk memberikan pelayanan 
maksimal kepada anak usia dini agar dapat mengembangkan berbagai potensi yang dimilikinya. Tentu saja dengan menyesuaikan dengan kemampuan anak dan orangtua masing-masing. Karena semakin lengkap layanan dan fasilitas yang diberikan akan berpengaruh pada beban biaya yang harus ditanggung oleh orangtua ke sekolah atau lembaga PAUD. Terdapat dua model program pendidikan anak usia dini di Indonesia saat ini yaitu program halfday dan fullday (M. Fadillah, 2015).

\section{Model Halfday}

Model halfday adalah model pendidikan setengah hari. Pendidikan anak usia dini yang melakukan model halfday yaitu proses belajar mengajarnya berlangsung hanya paruh waktu dalam sehari, mulai dari pukul 07.30 WIB sampai pukul 12.00 WIB. Program PAUD halfday lebih sederhana dibandingkan dengan program fullday. Secara umum program PAUD halfday dapat dilihat melalui uraian berikut ini: (1) Kelompok Bermain (KB) atau Tempat Penitipan Anak (TPA), (2) Kelompok Taman Kanak-kanak (TK) atau Raudatul Athfal (RA)

\section{Model Fullday}

Model fullday merupakan bentuk layanan pendidikan sehari penuh yang berlangsung dari pagi sampai sore hari. Program PAUD fullday dimulai dari pukul 07.30 sampai pukul 16.00 WIB. Kegiatannya pun jauh lebih banyak dan kompleks. Program PAUD fullday diperuntukkan bagi anak usia 0-6 tahun. Program ini dimanfaatkan oleh orang tua yang memiliki kesibukan yang sangat padat dan tidak ada waktu penuh untuk mendampingi anak-anaknya, baik sang ayah maupun sang ibu. Orang tua biasanya mengantarkan pada pagi hari sambil berangkat bekerja dan menjemputnya pada waktu sore hari setelah pulang bekerja.

PAUD fullday kebanyakan disukai oleh orang tua. Selain merasa aman, anak juga mendapatkan pelayanan pendidikan yang maksimal dari sekolah. Kemudian keperluan makan dan gizi juga telah disediakan oleh sekolah. Dibandingkan PAUD halfday, PAUD fullday jauh lebih mahal biaya administrasinya. Hal ini dikarenakan selama seharian penuh anak mengikuti berbagai kegiatan dan fasilitas yang diberikan oleh sekolah. 
Namun demikian, orangtua harus tetap meluangkan waktu untuk anaknya, minimal satu atau dua jam setiap hari. Bisa dilakukan sehabis maghrib atau setelah isya ketika akan menjelang tidur. Hal ini dimaksudkan supaya terjalin kedekatan antara orangtua dan anak, sehingga anak tetap merasa diperhatikan dan disayangi oleh orangtuanya.Adapun gambaran umum program PAUD fullday sebagai berikut: (1) Kelompok Bermain (KB) atau Tempat Penitipan Anak (TPA), (2) Kelompok Taman Kanak-Kanak (TK) atau Raudatul Athfal (RA)

Dari dua model program di atas selanjutnya dikembangkan dengan berbagai inovasi pembelajaran. Di antara inovasi-inovasi pendidikan anak usia dini di Indonesia adalah pendidikan anak usia dini berbasis alam, agraris, kebudayaan lokal, bencana alam, bilingual, dan religiusitas. Semua inovasi ini sangat tergantung pada lokasi atau kondisi geografis di mana lembaga PAUD itu berada. Inti dari inovasi pendidikan anak usia dini sendiri adalah sebagai upaya memberikan pelayanan yang terbaik dan berbeda dengan yang lain, serta sebagai upaya promosi untuk menarik minat anak-anak untuk bersekolah di tempat tersebut.

Kemudian selain inovasi dalam bentuk program, inovasi PAUD juga dapat dilakukan dalam proses pembelajaran. Dalam hal ini inovasi dimaksudkan untuk mempermudah peserta didik dalam memahami tema/materi pembelajaran. Selain itu, untuk menghilangkan rasa bosan anak dengan berbagai variasi pembelajaran. Inovasi pembelajaran yang biasa diterapkan dalam pendidikan anak usia dini ialah beyond center and circle time (BCCT).

\section{Beyond Center And Circle Time (BCCT)}

Model BCCT adalah suatu metode atau pendekatan dalam penyelenggaraan pendidikan anak usia dini dan merupakan perpaduan antara teori dan pengalaman praktik. BCCT merupakan konsep belajar dimana guru-guru menghadirkan dunia nyata dalam kelas dan mendorong siswa membuat hubungan antara pengetahuan yang dimiliki dengan penerapannya dalam kehidupan seharihari. Hasilnya adalah siswa memperoleh pengetahuan dan keterampilan dari konteks yang 
terbatas, sedikit demi sedikit dan dari proses mencoba sendiri sebagai bekal untuk memecahkan masalah dalam kehidupannya (Palupi, 2009).

Tujuan dari Model BCCT yang dimaknai sebagai sentra dan saat lingkaran adalah sebagai (Yuliani, 2013): (1) Model ini ditujukan untuk merangsang seluruh aspek kecerdasan anak (kecerdasan jamak) melalui bermain yang terarah. (2) Model ini ini menciptakan setting pembelajaran yang merangsang anak untuk aktif, kreatif, dan terus berpikir dengan menggali pengalamannya sendiri (bukan sekedar mengikuti perintah, meniru, atau menghafal).

Dilengkapi dengan standar operasional yang baku, yang berpusat di sentrasentra kegiatan dan saat anak berada dalam lingkaran bersama pendidik, sehingga mudah diikuti.

\section{Pembelajaran}

BCCT berdasarkan pada asumsi bahwa anak belajar melalui bermain dengan bendabenda dan orang-orang di sekitarnya (lingkungan). Dalam bermain anak berinteraksi dengan lingkungannya. Pengalaman bermain yang tepat dapat mengoptimalkan seluruh aspek perkembangan anak baik fisik, emosi, kognisi, maupun sosial anak. Pembelajaran dengan metode BCCT atau sering diartikan sebagai pendekatan sentra dan lingkaran (Kunarti, 2008), yaitu model pembelajaran yang dilakukan di dalam lingkaran dan sentra bermain (Mulyasa, 2012). Lingkaran adalah saat guru duduk bersama anak dengan posisi melingkar untuk memberikan pijakan kepada anak yang dilakukan sebelum dan sesudah bermain. Sedangkan sentra bermain adalah zona atau area bermain anak yang dilengkapi dengan seperangkat alat bermain, yang berfungsi sebagai pijakan lingkungan yang diperlukan untuk mengembangkan seluruh potensi dasar anak didik dalam berbagai aspek perkembangannya secara seimbang. Adapun beberapa sentra yang lazim digunakan di lembaga PAUD, antara lain: sentra imtaq, sentra bahan alam, sentra seni dan kreativitas, sentra bermain peran, sentra balok, sentra masak dan sentra persiapan (Suyadi, 2014).

Dalam kaitannya dengan model dan inovasi pendidikan anak usia dini sebagaimana telah disebutkan di atas, lembaga PAUD hendaknya 
memperhatikan rambu-rambu yang telah ditentukan. Pengembangan model maupun inovasi pendidikan anak usia dini harus senantiasa memperhatikan prinsip-prinsip pengembangan program pembelajaran PAUD. Hal ini dimaksudkan supaya program dan inovasi yang dikembangkan tetap sesuai dengan rambu-rambu yang telah ditentukan oleh pemerintah. Adapun prinsipprinsip yang dimaksud seperti memperhatikan karakteristik anak, memperhatikan konsep keahlian yang akan dikembangkan di dalam sentra, merumuskan tujuan dan manfaat sentra yang akan diajarkan, menentukan tempat sesuai kebutuhan, guru menjadi fasilitator, membatasi jumlah anak setiap sentra, mengajak anak untuk berpartisipasi aktif, dan menambah alat dan bahan-bahan baru ke setiap sentra (Luluk 2014).

\section{METODE PENELITIAN}

Penelitian ini menggunakan pendekatan kualitatif dengan rancangan study field research. Adapun tujuan yang hendak dicapai yaitu memperoleh gambaran, menjelaskan, dan menganalisis model maupun berbagai inovasi pendidikan anak usia dini di TPA SERAMA Kementerian Kesehatan RI. Subyek penelitian yang dipilih dalam penelitian ini ialah 10 orang siswa dan tenaga pendidik di TPA SERAMA Kementerian Kesehatan RI. Dengan teknik bola salju (snowball sampling) yang dapat dimintai informasi sehubungan dengan penerapan inovasi pendidikan anak usia dini dalam hal ini model program (halfday dan fullday) dan pembelajaran BCCT di TPA SERAMA Kementerian Kesehatan RI.

Subyek penelitian dipilih dengan menggunakan purposive sampling, yaitu pemilihan sampel dengan pertimbangan: (1) subyek penelitian terlibat langsung dlam proses implementasi model program dan pembelajaran dan (2) pihak yang menguasai permasalahan, memiliki data, dan bersedia memberi informasi (Moleong, 2006). Pengumpulan data penelitian ini dilakukan menggunakan metode wawancara dan observasi.

Analisis data dilakukan dengan menggunakan tiga alur kegiatan, yaitu reduksi data, penyajian data, dan penarikan kesimpulan atau verifikasi. 
Analisis yang digunakan untuk terstruktur yang meliputi pelatihan mendeskripsikan secara kualitatif.

psikososial dan motorik selama di TPA SERAMA Kementerian

\section{HASIL DAN PEMBAHASAN}

Kesehatan RI. Anak akan dilatih agar

Dari hasil penelitian yang lebih mengembangkan kemampuan dilakukan diketahui bahwa TPA motorik kasar, motorik halus, kognitif, SERAMA Kementerian Kesehatan bahasa, emosi dan sosial dalam bentuk merupakan sarana pengasuhan dan permainan ceria yang dipantau oleh pendidikan anak karyawan psikolog dan dokter. Program Kementerian Kesehatan, yang pendidikan yang berlangsung di TPA memiliki konsep utama sesuai dengan kurikulum Pedoman Teknis SERAMA Kementerian Kesehatan RI menerapkan pembelajaran sistem Penyelenggaraan TPA yang sentra, dengan jadwal kegiatan sebagai dikeluarkan oleh Menteri Pendidikan berikut:

Nasional tahun 2010. Anak atau bayi akan memperoleh program pendidikan

Tabel.

Jadwal Kegiatan Sentra

TPA SERAMA Kementerian Kesehatan RI

\begin{tabular}{|c|l|c|c|c|c|c|}
\hline No & \multicolumn{1}{|c|}{ Jenis } & Senin & Selasa & Rabu & Kamis & Jum'at \\
\hline 1 & Sentra Balok & V & & & & \\
\hline 2 & Sentra Seni & & V & & & \\
\hline 3 & Sentra Manipulatif & & & V & & \\
\hline 4 & Sentra Peran & & & & V & \\
\hline 5 & Sentra Persiapan & & & V & & \\
\hline 6 & Sentra Imtaq & & & & & V \\
\hline 7 & Sentra Bahan Alam & & & & V & \\
\hline
\end{tabular}

TPA SERAMA Kementerian Kesehatan RI menjalani model fullday. Waktu layanan dimulai pukul 08.00 16.00 WIB. Model ini sangat disukai oleh orangtua karena sangat sesuai dengan jam kerja mereka yang dimulai dari jam 07.30 - 16.00 WIB. Orangtua masih dapat mengunjungi anak mereka 210 saat mereka istirahat. Bagi orangtua yang masih memiliki usia 3 bulan masih dapat memberikan ASI eksklusif sesuai waktunya. Dengan kondisi seperti di atas, kebutuhan anak masih terpenuhi walaupun ibu tetap bekerja. Dalam kegiatan sehari-hari, anak menjalani proses pembelajaran 
sentra sesuai dengan tingkatan perkembangan atau usia anak. Sentrasentra yang dilakukan adalah sebagai berikut: (1) Sentra Balok. Sentra ini bertujuan mengembangkan kemampuan visuospasial, matematika, dan kreativitas anak dengan bermain rancang bangun. Kegiatan yang dilakukan anak di sentra balok seperti bermain balok membuat masjid, rumah, apartemen kereta api, jalan layang, pembangunan mass rapid transit (MRT). (2) Sentra Seni. Sentra ini bertujuan mengembangkan kemampuan seni rupa, bentuk, suara, musik, gerak, dan kreativitas. Kegiatan yang dilakukan anak di sentra seni adalah menggambar, melukis, mewarnai, bernyanyi, bermain alat musik, menari, membentuk obyek dengan slime dan playdough. (3) Sentra Manipulatif. Sentra ini bertujuan untuk meningkatkan keterampilan motorik halus, koordinasi mata dan tangan, mental, bahasa, dan keterampilan sosial. Kegiatan yang dilakukan anak di sentra manipulatif seperti melakukan aktivitas meronce, menjelujur, menisik, menjepit, mengenal warna, menyusun balok dan puzzle, mengenal bentuk dan warna, bermain congklak, memindahkan air ke dalam botol, memindahkan bola ke keranjang. (4) Sentra Peran. Sentra ini bertujuan untuk meningkatkan perkembangan kognisi, bahasa, sosioemosional anak. Kegiatan yang dilakukan anak di sentra peran seperti berperan melakukan aktivitas yang sering dilakukan dalam kehidupan seharihari, profesi (dokter, teller BANK, customer service, pedagang, security, perawat, guru, polisi, dan pemadam kebakaran). (5) Sentra Persiapan. Sentra ini bertujuan untuk memberikan kesempatan pada anak dalam mengembangkan kemampuan matematika, pra menulis dan membaca dengan kegiatan antara lain: mengurutkan, mengklasifikasikan, dan mengelompokkan berbagai aktivitas lainnya yang mendukung perkembangan kognitif anak. Kegiatan yang diberikan di sentra persiapan untuk membantu anak mempersiapkan diri memasuki sekolah dasar. Kegiatan yang dilakukan anak di sentra persiapan seperti berlatih berhitung dengan menggunakan balok-balok, mengenal angka dan huruf sambil bermain. (6) Sentra Iman dan taqwa 
(imtaq). Sentra ini bertujuan untuk menanamkan nilai-nilai agama, keimanan, dan ketaqwaan kepada Tuhan YME; mengembangkan kemampuan beragama pada anak sejak dini; dan membentuk pribadi yang cerdas berperilaku sesuai dengan norma-norma agama. Kegiatan yang dilakukan anak di sentra imtaq seperti mengenal tuhan, nabi, kitab, belajar gerakan sholat, mengaji, menghafal do'a-do'a pendek, menghafal surat pendek, belajar huruf hijaiyah, mengajarkan anak untuk beramal, gerakan wudhu, nilai-nilai agama dan kebaikan. (7) Sentra Bahan Alam. Sentra ini bertujuan untuk memberikan pengalaman pada anak untuk bereksplorasi dengan berbagai materi dan mengembangkan kemampuan sains dan sensorimotor anak.

Kegiatan yang dilakukan anak di sentra bahan alam seperti bercocok tanam, mengenal hujan, mengenal pantai, berkunjung ke taman obat untuk mengenal berbagai jenis tanaman obat, mengenal flora dan fauna.

Proses pembelajaran yang berlangsung secara alamiah di mana siswa mengalami apa yang dipelajari, 212 bukan transfer pengetahuan dari guru ke siswa sehingga strategi pembelajaran lebih penting daripada hasil. Guru tidak lupa memberikan reward dalam proses pembelajaran ketika anak mampu menampilkan perilaku/kemampuan yang diharapkan.

Evaluasi selalu dilakukan setiap saat menjalankan program pembelajaran. Pencapaian hasil pembelajaran dilakukan pada semua anak sesuai dengan kemampuan dan usia perkembangannya sehingga evaluasi dilakukan secara individual. Dengan demikian, kegiatan pembelajaran yang berlangsung akan semakin lebih baik pada pertemuan selanjutnya.

Namun implementasi pada proses pembelajaran BCCT tidak didukung sepenuhnya oleh pihak manajemen dalam hal ini adalah pimpinan manajemen. Banyak masukan yang diberikan oleh orangtua siswa dan tenaga pendidik TPA SERAMA Kementerian Kesehatan RI untuk meningkatkan kualitas pembelajaran yang diberikan guru ke siswa kurang direspon. Pada akhirnya, kreativitas guru sangat menentukan keberlangsungan proses pembelajaran 
BCCT secara optimal walaupun dalam keterbatasan.

\section{KESIMPULAN}

Berdasarkan uraian dari pembahasan hasil penelitian yang ditemukan pada implementasi inovasi pendidikan anak usia dini di TPA SERAMA Kementerian Kesehatan RI yaitu dengan menggunakan model program dan proses pembelajaran yang berlangsung adalah model program fullday sangat sesuai dengan TPA SERAMA Kementerian Kesehatan RI, dimana waktu operasionalnya sesuai dengan jam kerja orangtua sehingga ibu masih bisa memberikan pengasuhan pada anaknya. Pelaksanaan proses pembelajaran BCCTpun dapat berlangsung secara optimal walau tidak mendapatkan dukungan sepenuhnya dari pihak manajemen terkait dengan pengembangan program yang diusulkan baik dari orangtua maupun tenaga kependidikan TPA SERAMA Kementerian Kesehatan RI.

\section{REKOMENDASI}

Berdasarkan temuan di lapangan selanjutnya disampaikan beberapa saran-saran sebagai berikut: Tenaga pendidik TPA SERAMA Kementerian Kesehatan RI agar selalu mengembangkan diri dalam menerapkan proses pembelajaran BCCT dengan membaca pengetahuan dan mengikuti pelatihan mengenai metode pembelajaran BCCT. Kepala TPA SERAMA Kementerian Kesehatan RI agar berani menyampaikan semua masukan baik yang berasal dari orangtua dan tenaga pendidik terkait dengan perbaikan implementasi proses pembelajaran BCCT. Kepala TPA harus berusaha keras untuk menyelesaikan permasalahan yang dihadapi oleh tenaga pendidik agar proses pembelajaran BCCT dapat berlangsung secara optimal. (3) Pihak manajemen TPA SERAMA Kementerian Kesehatan RI khususnya adalah pimpinan manajemen agar merespon segala masukan yang diberikan oleh kepala TPA, tenaga pendidik, dan orangtua secara positif sehingga proses pembelajaran BCCT dapat berlangsung secara optimal dan kualitas pendidikan di TPA SERAMA Kementerian Kesehatan RI semakin baik. 


\section{DAFTAR PUSTAKA}

Aisyah, Siti. Perkembangan dan Konsep Dasar Pengembangan Anak Usia Dini. Jakarta: Universitas Terbuka, 2014.

Asmawati, Luluk. Perencanaan Pembelajaran PAUD. Bandung: Rosda, 2014.

Berk, Laura E. 2012. Development Throught the Lifespan. Yogyakarta: Pustaka Pelajar.

Essa, Eva L. Introduction to Early Childhood Education $7^{\text {th }} E d$. Canada: Thomson Learning Inc, 2014.

Esti, Palupi. Metode Pembelajaran BCCT, dalam http://jurnaljpi.wordpress.com diunduh tanggal 5 Januari 2015.

Fadillah, M. Ragam dan Inovasi Pendidikan Anak Usia Dini. Prosiding Seminar Nasional Pendidikan Inovasi Pembelajaran untuk Pendidikan Berkemajuan, 2015.

Kemendiknas.

Pedoman Pengembangan Program Pembelajaran di Taman KanakKanak. Jakarta: Direktorat Pembinaan Taman Kanak-Kanak dan Sekolah Dasar, 2010.

Kunarti. Penerapan Pendekatan BCCT dan Kurikulum Sesuai Perkembangan Anak Usia Dini. Semarang: UNS, 2008.

Malinton, Sherly. Studi Tentang Pelayanan Anak di Taman Penitipan Anak Puspa Wijaya I Tenggarong. eJournal SosiatriSosiologi, 2013.

Moleong, Lexy, J. Metodologi Penelitian Kualitatif. Bandung: Remaja Rosdakarya, 2006.
Morrison. George S. Dasar-Dasar Pendidikan Anak Usia Dini. Jakarta: Indeks, 2012.

Mulyasa. Manajemen PAUD. Bandung: Rosdakarya, 2012.

Permendiknas No. 58 tahun 2009 tentang Standar Nasional Pendidikan Anak Usia Dini.

Santoso, Soegeng. Konsep Pendidikan Anak Usia Dini Menurut Pendirinya. Jakarta: UNJ, 2011.

Sujiono, Yuliani N. Konsep Dasar Pendidikan Anak Usia Dini. Jakarta: Indeks, 2009.

Sujiono, Yuliani N. Konsep Dasar Pendidikan Anak Usia Dini. Jakarta: Indeks, 2013.

Suyadi. Implementasi dan Inovasi Kurikulum PAUD 2013. Bandung: PT Remaja Rosdakarya, 2014.

Suyanto, Slamet. Konsep Dasar Pendidikan Anak Usia Dini. Jakarta: Depdiknas, 2005.

Undang-Undang Nomor 20 tahun 2003 tentang Sistem Pendidikan Nasional. 